\title{
Pharmacokinetic Targets for Therapeutic Drug Monitoring of Small Molecule Kinase Inhibitors in Pediatric Oncology
}

\author{
Julie M. Janssen $^{1, *}$, Thomas P. C. Dorlo ${ }^{1}$, Neeltje Steeghs ${ }^{2}$, Jos H. Beijnen ${ }^{1,3}$, Lidwien M. Hanff ${ }^{4}$, \\ Natasha K. A. van Eijkelenburg ${ }^{4}$, Jasper van der Lugt ${ }^{4}$, C. Michel Zwaan ${ }^{4,5}$ and Alwin D. R. Huitema ${ }^{1,6}$
}

In recent years new targeted small molecule kinase inhibitors have become available for pediatric patients with cancer. Relationships between drug exposure and treatment response have been established for several of these drugs in adults. Following these exposure-response relationships, pharmacokinetic (PK) target minimum plasma rug concentration at the end of a dosing interval $\left(C_{\text {min }}\right)$ values to guide therapeutic drug monitoring (TDM) in adults have been proposed. Despite the fact that variability in PK may be even larger in pediatric patients, TDM is only sparsely applied in pediatric oncology. Based on knowledge of the PK, mechanism of action, molecular driver, and pathophysiology of the disease, we bridge available data on the exposure-efficacy relationship from adults to children and propose target $C_{\min }$ values to guide TDM for the pediatric population. Dose adjustments in individual pediatric patients can be based on these targets. Nevertheless, further research should be performed to validate these targets.

The number of targeted small molecule kinase inhibitors (KIs) approved for the treatment of cancer in adults is rapidly expanding, which has led to increased pediatric treatment options as well. Over the past two decades, efforts have been made by clinicians and regulatory agencies to increase the incorporation of pediatric research into the registration processes. ${ }^{1}$ This includes the requirement to agree on a pediatric investigational plan before an adult marketing access can be obtained in Europe and several extrapolation approaches that use existing information in the adult population to accelerate pediatric development. ${ }^{2,3}$ However, since the type of adult cancer for which a drug is approved often does not occur in children, waivers are frequently granted for pediatric development, and it has been argued that in fact a target-based waiver system would be more appropriate. ${ }^{4}$

Up to 2016, only two KIs had been approved by the US Food and Drug Administration (FDA) for the treatment of childhood cancers: Imatinib for Philadelphia chromosome-positive $(\mathrm{Ph}+)$ chronic myeloid leukemia (CML) and everolimus for subependymal giant-cell astrocytoma. ${ }^{2,3}$ Only recently, dasatinib, nilotinib, and larotrectinib have been approved by the FDA for the treatment of pediatric cancers. ${ }^{5,6}$ To incentivize the pediatric development of approved adult KIs in oncology, the European Medicines Agency (EMA) and FDA both provide guidance for pediatric study plans based on expression of molecular targets.

Large pharmacokinetic $(\mathrm{PK})$ variability has been observed for almost all of the KIs approved in adults. A broad range of factors, such as genetics, food intake, drug formulation, and use of concomitant medication may influence the absorption, distribution, metabolism, and excretion of drugs. ${ }^{7-9}$ As a result of changing body composition, body size, maturation of organ functions, and treatment compliance, additional dimensions of variability in PK are present in pediatric patients. ${ }^{10}$ Resulting variability in exposure may, especially in children, lead to suboptimal efficacy or substantial toxicity caused by low or high drug exposure, respectively. Hence, by using exposure-efficacy relationships, dose adaptation based on therapeutic drug monitoring (TDM) may optimize treatment of pediatric patients treated with anticancer KIs. In fact, TDM to improve pediatric treatment outcomes has proven its value in nononcology diseases like posttransplantation and in infectious diseases. ${ }^{11,12}$

Practical recommendations for TDM of KIs in the adult setting have been proposed and proven beneficial for several anticancer drugs and indications. ${ }^{13-15}$ Despite this existing knowledge, TDM is still only sparsely applied, particularly in pediatric oncology. The majority of KIs that are being investigated for the treatment of pediatric malignancies are currently still in early stages of development. Consequently, quantitative exposure-response and exposure-toxicity relationships have not yet been established for these drugs in relation to pediatric indications. Therefore, the aim of this review is to elaborate on the current knowledge on exposureresponse relationships of KIs in pediatric oncology, and if exposure-response relationships are lacking to summarize the available clinical exposure and response data in pediatric and adult patients. The ultimate goal is to evaluate the available information in order to propose empirical and practical targets, to guide TDM of KIs in pediatric oncology.

\footnotetext{
${ }^{1}$ Department of Pharmacy \& Pharmacology, Antoni van Leeuwenhoek/Netherlands Cancer Institute, Amsterdam, The Netherlands; ${ }^{2}$ Department of Clinical Pharmacology, Division of Medical Oncology, Antoni van Leeuwenhoek/Netherlands Cancer Institute, Amsterdam, The Netherlands; ${ }^{3}$ Utrecht Institute for Pharmaceutical Sciences (UIPS), Utrecht University, Utrecht, The Netherlands; ${ }^{4}$ Princess Máxima Center for Pediatric Oncology, Utrecht, The Netherlands; ${ }^{5}$ Department of Pediatric Hematology and Oncology, Erasmus Medical Center, Rotterdam, The Netherlands; ${ }^{6}$ Department of Clinical Pharmacy, University Medical Center Utrecht, Utrecht University, Utrecht, The Netherlands. *Correspondence: Julie M. Janssen (ju.janssen@nki.nl) 


\section{DETERMINATION OF TDM TARGETS IN PEDIATRIC MALIGNANCIES}

The literature was searched for pediatric PK data on KIs for which adult thresholds have previously been proposed. PubMed searches were performed using the following search terms: $((((((($ pediatric[Title/Abstract]) OR pediatrics[Title/Abstract] $)$ OR paediatric[Title/Abstract]) OR paediatrics[Title/Abstract]) OR pediatric patient[Title/Abstract]) OR paediatric patient [Title/Abstract]) OR child[Title/Abstract]) OR children[Title/ Abstract])) AND (imatinib OR glivec) for afatinib, alectinib, axitinib, bosutinib, cabozantinib, ceritinib, cobimetinib, crizotinib, dabrafenib, dasatinib, erlotinib, everolimus, gefitinib, ibrutinib, idelalisib, imatinib, lapatinib, lenvatinib, nilotinib, nintedanib, osimertinib, palbociclib, pazopanib, ponatinib, regorafenib, sorafenib, sunitinib, trametinib, vandetanib and vemurafenib. Additionally, the FDA Clinical Pharmacology and Biopharmaceutics Review and the Committee for Medicinal Products for Human Use European Public Assessment Report were reviewed for pediatric data.

Determination of a target was performed in a stepwise manner as described in Figure 1. A practical PK target was defined as the minimally required drug exposure for efficacy, which is feasible to measure or to extrapolate in clinical practice for the pediatric population. When a pharmacokinetic-pharmacodynamic (PK-PD) relationship in pediatric patients has been described in literature, the corresponding cutoff minimum plasma drug concentration at the end of a dosing interval $\left(\mathrm{C}_{\text {min }}\right)$ that was related to improved efficacy was proposed to guide pediatric TDM (level A in Figure 1). When such a relationship was not available but the target and the disease pathophysiology was deemed similar compared with adults, the adult target that was previously proposed was used (level B). ${ }^{13}$ When an exposure-response relationship in adults was not available but the disease pathophysiology was considered similar in adult and pediatric patients, the average exposure in adults that corresponds to the therapeutic dose was proposed as an exploratory target to guide pediatric dosing (level C). When the molecular target was similar in adult and pediatric patients but the pathophysiology of the disease was different (level D), the proposed adult target (either derived from an exposure-response relationship or the average exposure at the approved dose) was used. Furthermore, if in this case pediatric PK data were available, the average exposure in pediatric patients was proposed as an exploratory target (both levels D and E).

\section{PRACTICAL RECOMMENDATIONS FOR TDM OF KIS IN PEDIATRIC MALIGNANCIES}

Based on the identified literature, recommendations for pediatric targets were defined. Table 1 provides an overview of the included drugs, the previously published targets in adults, and the proposed targets in pediatric patients.

\section{ANAPLASTIC LYMPHOMA KINASE INHIBITORS}

The anaplastic lymphoma kinase (ALK) gene has initially been identified as the fusion gene in anaplastic large cell non-Hodgkin's lymphoma (ALCL), which accounts for $10-15 \%$ of all childhood lymphomas. ALK fusions have also been identified in pediatric inflammatory myofibroblastic tumors and infant high grade gliomas. Activating kinase domain mutations or gene amplifications of the full-length ALK receptor have been identified in $8 \%$ of neuroblastoma patients. ${ }^{16}$ In adult nonsmall cell lung cancer (NSCLC), translocations in ALK have been identified as a key driver in the malignant process. It has been shown that the inhibition of mutant ALK is more complex compared with translocated ALK in NSCLC. Based on the variability in underlying molecular changes in the $A L K$ gene and based on the variability in response in NSCLC, the biology of ALK in pediatric cancer patients may differ from that in adults. Hence, sensitivity to treatment with ALK inhibitors

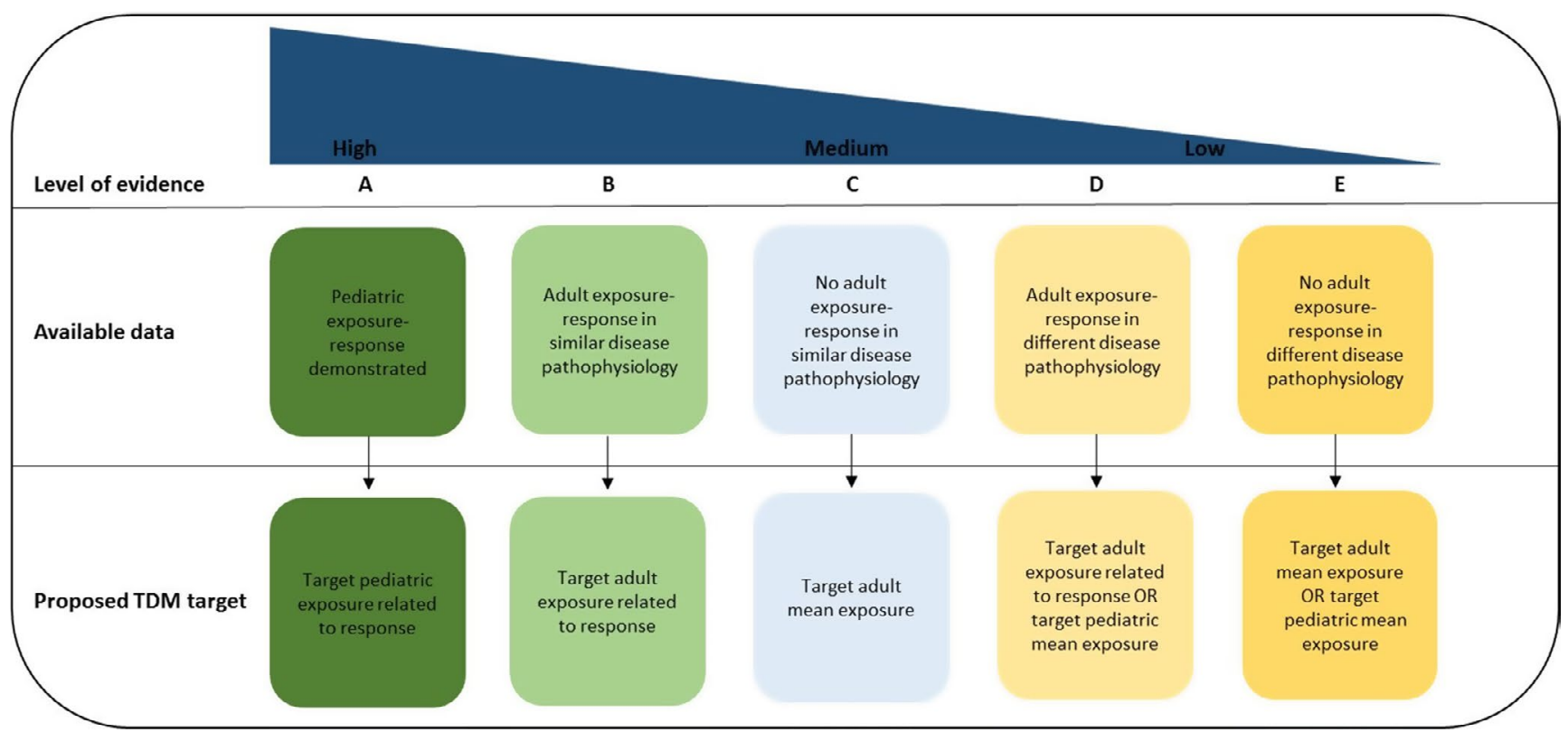

Figure 1 Framework to guide TDM in pediatric oncology. TDM, therapeutic drug monitoring. 
Table 1 Proposed TDM targets for KIs in pediatric oncology

Pediatric

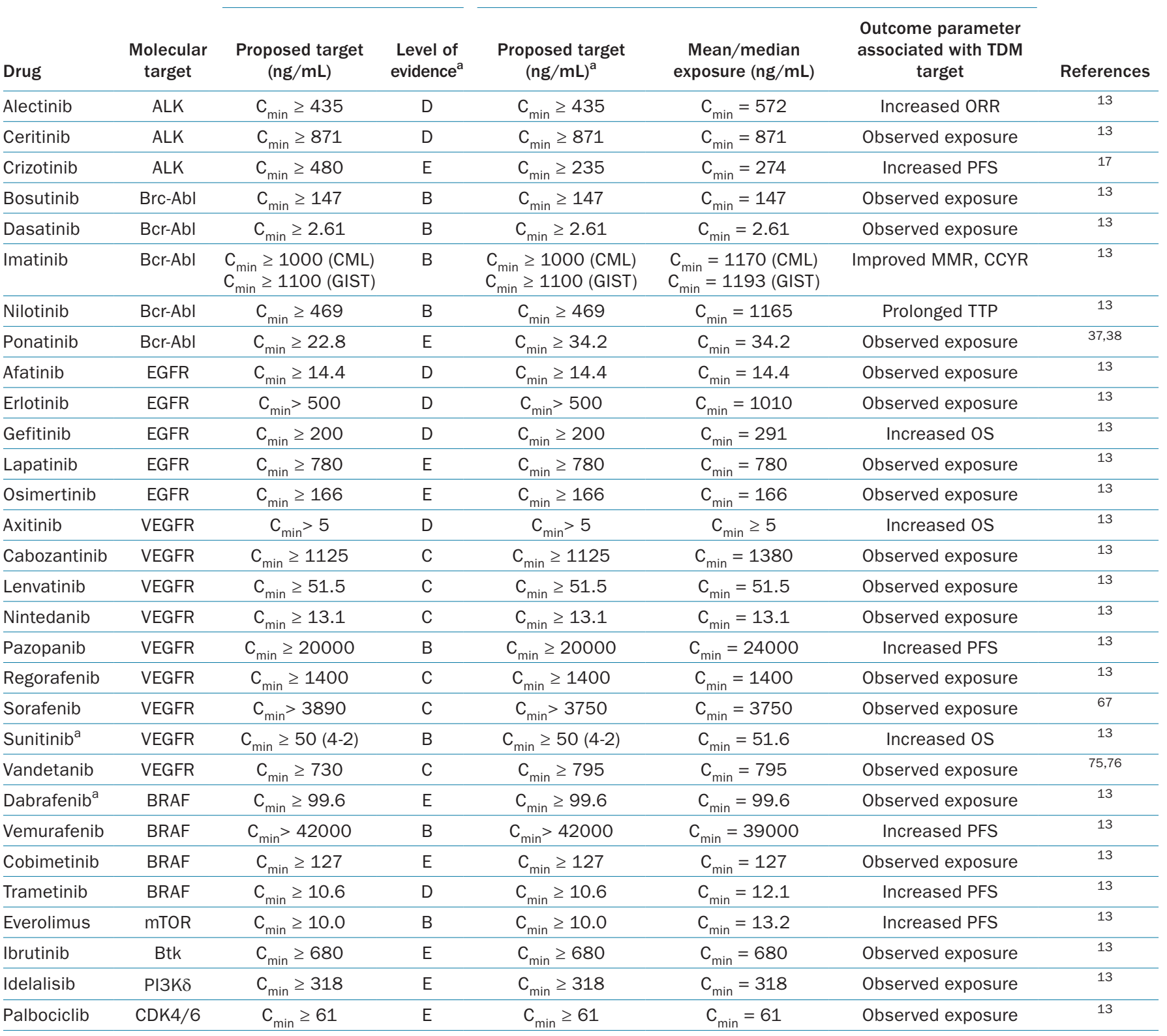

ALK, anaplastic lymphoma kinase; Bcr-Abl, breakpoint cluster region-abelson; BRAF, serine/threonine-protein kinase B-raf; Btk, Bruton's tyrosine kinase; CCYR, complete cytogenetic response; CDK4/6, cyclin-dependent kinases 4 and 6; $\mathrm{C}_{\min }$, minimum plasma drug concentration at the end of a dosing interval; CML, chronic myeloid leukemia; EGFR, epidermal growth factor receptor; GIST, gastrointestinal stromal tumor; KIs, small molecule kinase inhibitors; MMR, major molecular response; mTOR, mammalian target of rapamycin; PFS, progression free survival; PI3K $\delta$, phosphatidylinositide 3-kinase; ORR, objective response rate; OS, overall survival; TDM, therapeutic drug monitoring; TTP, time to progression; VEGFR, vascular endothelial growth factor receptor.

${ }^{a}$ (A) Pediatric exposure-response demonstrated; (B) Adult exposure-response in similar disease pathophysiology; (C) No adult exposure-response in similar disease pathophysiology; (D) Adult exposure-response in different disease pathophysiology; (E) No adult exposure-response in different disease pathophysiology. ${ }^{b}[13] .{ }^{c}$ Sum of sunitinib \& N-desethylsunitinib. ${ }^{d}$ Sum of dabrafenib \& hydroxyl-dabrafenib.

may also differ between pediatric patients and adults. ${ }^{16,17} \mathrm{We}$ here describe ALK inhibitors for which target $C_{\text {min }}$ values in adults have been proposed.

\section{Crizotinib}

In a study investigating crizotinib for the treatment of pediatric relapsed/refractory ALK-positive ALCL, an objective response rate (ORR) of $90 \%$ was observed $\left(n=26\right.$, age range $3.7-20.8$ years old). ${ }^{17}$
At the maximum tolerated dose $\left(280 \mathrm{mg} / \mathrm{m}^{2}\right.$ b.i.d.), the mean $\mathrm{C}_{\min }$ in pediatric patients was $480 \mathrm{ng} / \mathrm{mL}$, corresponding to a free drug concentration of $50 \mathrm{ng} / \mathrm{mL}$. ${ }^{18}$ The unbound drug concentration of $50 \mathrm{ng} / \mathrm{mL}$ exceeds the concentration of drug producing $50 \%$ inhibition of $10 \mathrm{ng} / \mathrm{mL}$ of crizotinib in ALCL cell lines. No relationships between exposure and efficacy have been established for crizotinib in adults with NSCLC nor pediatric patients with ALCL. ${ }^{13}$ Therefore, the best estimate for a minimum target for efficacy 
would be the mean pediatric $\mathrm{C}_{\min }$ of $480 \mathrm{ng} / \mathrm{mL}$. Further research is, however, needed to confirm this preliminary recommendation.

\section{Ceritinib}

A phase I study with ceritinib in pediatric patients with ALCL, inflammatory myofibroblastic tumor, rhabdomyosarcoma, or neuroblastoma $(n=22$, age range $2-17$ years old) reported similar area under the concentration-time curve (AUC) and apparent total clearance as in adults at the recommended dose for expansion $\left(510 \mathrm{mg} / \mathrm{m}^{2}\right.$ q.d.). Detailed results on exposure (AUC) and clearance were not reported. ${ }^{19}$ In adults with ALK positive NSCLC, only a trend towards higher ORR with higher $\mathrm{C}_{\min }$ could be identified. ${ }^{20}$ Thus, the mean $\mathrm{C}_{\min } \geq 871 \mathrm{ng} / \mathrm{mL}$ that was reported in adults may provide preliminary guidance for individualized dosing in pediatric patients, until further information regarding the pediatric application is available.

\section{Alectinib}

There are no clinical studies available in which alectinib has been used in the treatment of pediatric malignancies. In adults with ALK positive NSCLC, a steady-state $\mathrm{C}_{\min } \geq 435 \mathrm{ng} /$ $\mathrm{mL}$ has been proposed as a target to guide TDM of alectinib. Patients with a steady-state $\mathrm{C}_{\min }$ above this target showed a larger reduction in tumor size compared with patients with a steady-state $\mathrm{C}_{\min }$ below $435 \mathrm{ng} / \mathrm{mL} .{ }^{21}$ As described above, the biology of ALK may be different in pediatric malignancies. Extrapolation of exposure-response relationships from adults with NSCLC to children with other forms of malignancies may therefore not be appropriate. In addition, the $\mathrm{C}_{\min }$ in pediatric patients was unavailable. Thus, no specific threshold can be proposed at this time.

\section{BREAK POINT CLUSTER REGION - ABELSON ONCOPROTEIN INHIBITORS}

CML represents $2-3 \%$ of pediatric leukemias, with increasing incidence with age. $\mathrm{Ph}+\mathrm{CML}$ patients are treated with break point cluster region - Abelson (Bcr-Abl) inhibitors. Studies have shown that CML biology is slightly different in pediatric and adult disease. ${ }^{22} \mathrm{~A}$ clear explanation for the difference in disease response has however not yet been found. Therefore, established exposure-response relationships for $\mathrm{Bcr}-\mathrm{Abl}$ inhibitors in adults can be extrapolated to children with some caution. ${ }^{23}$ Efforts should be made to identify exposure-response relationships in pediatric disease.

\section{Imatinib}

Several clinical studies in pediatric patients with CML have shown that the PK of imatinib and its active metabolite (CGP74588) in children and adults are similar when children are treated with a body surface area (BSA)-based equivalent dose $\left(260 \mathrm{mg} / \mathrm{m}^{2}\right.$ q.d.). Two population PK analyses identified body weight as a significant covariate on imatinib clearance. The inclusion of age did not improve the model and was thus not included. ${ }^{24,25}$ Additionally, steady-state plasma concentrations in children with solid tumors were similar to the steadystate plasma concentrations in children and adults with CML following body weight-based dosing. ${ }^{26}$ Nevertheless, information on the PK of imatinib during the first 2 years of age is lacking. Multiple trials in adults confirmed that the target $\mathrm{C}_{\min }$ of $\geq 1000 \mathrm{ng} / \mathrm{mL}$ is associated with a better treatment outcome. ${ }^{13}$ Until data on the pediatric exposure-response become available, we recommend the well-established exposure-response based adult target $C_{\min } \geq 1000 \mathrm{ng} / \mathrm{mL}$ as a minimum target for dose individualization in children with CML.

Alongside its use in CML, imatinib has also been used to treat pediatric gastrointestinal stromal tumors (GIST). For this indication, imatinib is targeted against the stem cell receptor (KIT) and platelet-derived growth factor receptor (PDGFR). ${ }^{27}$ It has been shown that pediatric GIST has a different pathophysiology and presentation than adult GIST. Genetic mutations in KIT or PDGFR are rare in pediatric patients, and tumors are more often located in the stomach. ${ }^{28}$ Adult studies showed a significant increase in progression-free-survival (PFS) with increased $\mathrm{C}_{\min }{ }^{29}$ As it has been shown that the PK in pediatric and adult patients was similar in patients with CML and in patients with solid tumors, we propose the adult $\mathrm{PK}$ target of $\mathrm{C}_{\min } \geq 1100 \mathrm{ng} / \mathrm{mL}$ for dose individualization in pediatric GIST as an exploratory target.

\section{Dasatinib}

A large phase II trial with dasatinib in chronic phase CML showed similar to or higher efficacy of dasatinib in pediatric patients compared with historically observed efficacy in adults $(n=60$, age range 1.5-27.6 years old). Children were treated with a BSA-based dose $\left(60 \mathrm{mg} / \mathrm{m}^{2}\right.$ q.d.) that was equivalent to the approved adult flat dose. ${ }^{30}$ In a phase I study, the dasatinib $\mathrm{AUC}_{0 \text {-last }}$ in pediatric patients $(n=58$, age range $<2$ years -18 years old) treated with a BSA-based dose has been reported to be similar to the exposure that has been observed in adults; the AUC in adults was, however, not reported. ${ }^{31}$ An exposure-response relationship in pediatric patients has not been established as far as we know. In a population PK-PD analysis of the adult clinical trials with dasatinib, the weighted average steady-state concentration has been related to major cytogenetic response (2.11-fold increase of the odds of response for every doubling of the average steady-state concentration). ${ }^{32}$ Given the clear exposure-efficacy relationship in adults and similarity in PK between adult and pediatric patients, using the geometric mean $\mathrm{C}_{\min }$ of $2.61 \mathrm{ng} / \mathrm{mL}$ that was observed in adults seems justified as a minimum TDM target for pediatric patients.

\section{Nilotinib}

The PK of nilotinib has been investigated in pediatric patients with $\mathrm{Ph}+\mathrm{CML}$ or acute lymphoblastic leukemia (ALL) $(n=15)$. Here it has been shown that $C_{\min }$ achieved with BSA-based dosing $\left(230 \mathrm{mg} / \mathrm{m}^{2}\right.$ b.i.d.) was slightly lower in both children aged $1-<10$ years old (mean $\mathrm{C}_{\min } 804.8 \mathrm{ng}$ / $\mathrm{mL}$ ) and children aged $10-<18$ years old (mean $\mathrm{C}_{\min } 1073 \mathrm{ng} /$ $\mathrm{mL}$ ) compared with adults (mean $\mathrm{C}_{\min } 1165 \mathrm{ng} / \mathrm{mL}$ ). ${ }^{33}$ Several exposure-response relationships have been established by population PK-PD analyses of adult patient data; however, information on this relationship in pediatric patients is still lacking. Most importantly, a significantly longer time to complete 
cytogenetic response or major molecular response and short time to progression have been identified for adult patients in the lowest $\mathrm{C}_{\min }$ quartile compared with the higher quartiles. The lowest quartile threshold $\mathrm{C}_{\min }$ was $469 \mathrm{ng} / \mathrm{mL}$ for these analyses. ${ }^{34}$ Considering the strong exposure-efficacy relationship in adults, a $\mathrm{C}_{\min } \geq 469 \mathrm{ng} / \mathrm{mL}$ is recommended for TDM of nilotinib in pediatric patients.

\section{Bosutinib}

The first phase I/II study of bosutinib in pediatric patients with CML is currently ongoing (European Union Drug Regulating Authorities Clinical Trials Database (EudraCT) no. 2015002916-34). In adults with CML, associations between PK and complete cytogenetic response, complete hematological response, and major molecular response have been shown. Additionally, in the pivotal adult CML trial, the $\mathrm{C}_{\text {min }}$ was reported to be higher in responders than in nonresponders. ${ }^{35}$ We recommend the median adult $\mathrm{C}_{\min }$ of $147 \mathrm{ng} / \mathrm{mL}$ as a minimum threshold for TDM in pediatric patients with CML, while awaiting the results of clinical trial in pediatric patients.

\section{Ponatinib}

Preclinical studies have shown that a ponatinib concentration of $40 \mathrm{nM}$ suppressed the emergence of any single mutation. ${ }^{36}$ In adults, a statistically significant relationship between dose intensity and probability of major cytogenetic responses in patients with CML has been described. It has additionally been shown that toxicity was dose dependent. The use of ponatinib in pediatric patients is still rare. Hence, pediatric PK and exposure-response data are not available. ${ }^{37}$ Case reports suggested that ponatinib treatment is effective in children with $\mathrm{Ph}+\mathrm{ALL}$ or CML. ${ }^{38,39}$ Based on the relationship between daily dose and toxicity that has been described in adults, the dose was lowered in the described pediatric cases. With this dose (15 mg q.d.), the serum concentration of ponatinib was $18.3 \mathrm{ng} / \mathrm{mL}$ at 9 hours after dose at the last treatment day, which is slightly below the reported active concentration ( $40 \mathrm{nM} ; 22.8 \mathrm{ng} / \mathrm{mL}$ ). Given the very limited evidence available, no specific target can be proposed for ponatinib.

\section{EPIDERMAL GROWTH FACTOR RECEPTOR INHIBITORS}

The amplification of epidermal growth factor receptor (EGFR) has been observed in 5-10\% of pediatric high-grade gliomas (HGGs), and overexpression of EGFR is seen in over $80 \%$ of pediatric malignant gliomas. Pediatric HGGs are regarded as genetically different and more malignant tumors than adult brain tumors. ${ }^{40-44}$ In adults, EGFR inhibitors are predominantly applied in EGFR mutated NSCLC. Analogy between NSCLC and brain tumors has not yet been demonstrated. Moreover, penetration of EGFR inhibitors in brain tumors may be limited by the blood-brain barrier, and, therefore, higher plasma concentrations may be needed for adequate target inhibition. It is therefore challenging to extrapolate the pediatric target $C_{\text {min }}$ from adults to children with various brain tumors.

\section{Gefitinib}

The exposure of gefitinib in pediatric patients $(n=17$, age range 1.8-21.2 years old) with solid tumors has been shown to be consistent with prior knowledge in adults. ${ }^{42}$ Gefitinib apparent clearance was $13.7 \pm 6.6 \mathrm{~L} /$ hour $/ \mathrm{m}^{2}$ in children younger than 12 years $(n=10)$ and $14.4 \pm 6.9 \mathrm{~L} /$ hour $/ \mathrm{m}^{2}$ in children older than 12 years $(n=7)$. In addition, median steady-state $\mathrm{AUC}_{0-24 \mathrm{~h}}$ estimates were similar in pediatric patients compared with adults. These findings have been confirmed in a PK analysis of 19 pediatric patients with newly diagnosed brainstem glioma (BSG). In an additional exploratory analysis, no evidence of a relationship between gefitinib PK and toxicity or efficacy has been identified. Moreover, the $\mathrm{AUC}_{0-24 \mathrm{~h}}$ achieved in children dosed $250 \mathrm{mg} / \mathrm{m}^{2} /$ day (11800 ng/mL*hour, $n=6)$ were comparable with the $\mathrm{AUC}_{0 \text { - }}$ $24 \mathrm{~h}$ that was associated with antitumor activity in adults with solid tumors $\left(8596 \mathrm{ng} / \mathrm{mL}^{*}\right.$ hour, $\left.n=7\right) .{ }^{41,45}$ In a study with adult NSCLC patients, a $C_{\text {min }} \geq 200 \mathrm{ng} / \mathrm{mL}$ has been associated with a significantly higher overall survival (4.7 months vs. 14.6 months, $P=0.007) .{ }^{13,46}$ Given the clear exposure-efficacy relationship in adults with NSCLC and absence of sufficient pediatric PK data and data on target inhibition in pediatric solid tumors and BSG, a preliminary $\mathrm{C}_{\min } \geq 200 \mathrm{ng} / \mathrm{mL}$ may provide guidance for dosing in pediatric patients.

\section{Erlotinib}

In population $\mathrm{PK}-\mathrm{PD}$ analyses including adults with head and neck carcinoma $(n=42)$ and pediatric patients $(n=46$, age range 2-19 years old) with malignant brain tumors, a significantly higher elimination capacity in children was identified $(P<0.0001)$ compared with adults. ${ }^{47,48}$ Typical clearance values of $0.146 \mathrm{~L} /$ hour $/ \mathrm{kg}$ and $0.095 \mathrm{~L} /$ hour $/ \mathrm{kg}$ have been found for children and adults, respectively, resulting in a higher recommended dose in children (125 vs. $90 \mathrm{mg} / \mathrm{m}^{2}$ q.d. in adults). As a result of heterogeneity in disease status between patients at time of enrollment, a relationship between exposure and response could not be established. ${ }^{49}$ In the pediatric population, only AUC values have been reported but TDM based on AUC is difficult to implement. Until new data is available on the PK and brain penetration of erlotinib in pediatric patients with malignant brain tumors, the target that was proposed in adults, i.e., $\mathrm{C}_{\min }>500 \mathrm{ng} / \mathrm{mL}$, could be used as a preliminary starting point for pediatric dose individualization. ${ }^{13}$

\section{Lapatinib}

Since the human epidermal growth factor receptor 2 (HER2) has been shown to play an important role in the pathophysiology of pediatric ependymomas, medulloblastomas, and BSG, lapatinib has been investigated in children with these malignancies. In these clinical trials, lapatinib was administered in a twice-daily dose. It is therefore not possible to compare $\mathrm{PK}$ data in children to those obtained in adults. The pediatric $\mathrm{C}_{\min }$ (data not reported) was reported to be similar to the limited data that were obtained from adults treated with twice-daily lapatinib. ${ }^{50,51}$ The proposed adult TDM target of $\mathrm{C}_{\text {min }} \geq 780 \mathrm{ng} / \mathrm{mL}$ has been based on the mean adult steady-state $C_{\text {min }}$ at the standard dose (1500 mg q.d.), and is therefore not appropriate as a target for pediatric TDM. Future studies should focus on exposure-response and exposure-toxicity relationships in pediatric brain tumors, in order to establish a valid target for lapatinib TDM in pediatric diseases. 


\section{Afatinib}

Afatinib is currently under investigation for the treatment of pediatric patients with HGG, diffuse intrinsic pontine glioma, low grade astrocytoma, medulloblastoma, ependymoma, neuroblastoma, rhabdomyosarcoma, and tumors with known ErbB pathway deregulation (NCT-02372006). ${ }^{52}$ A relationship between exposure and response has not yet been reported for afatinib in both pediatric and adult patients. However, it has been found that the $\mathrm{C}_{\text {min }}$ in adults experiencing Grade 3 diarrhea was higher than those experiencing Grade 1-2 diarrhea ( 35.8 vs. $25.2-31.6 \mathrm{ng} / \mathrm{mL}$ ). ${ }^{53}$ Considering the very limited available data on the PK and brain penetration of afatinib in pediatric patients, extrapolation from data obtained from adults with NSCLC may be inappropriate. It could be considered to use the mean steady-state $\mathrm{C}_{\min }$ found in adult patients, i.e., $14.4 \mathrm{ng} / \mathrm{mL}$, as an exploratory minimum target for pediatric TDM. ${ }^{13}$

\section{Osimertinib}

To date osimertinib has not been investigated in pediatric malignancies. Nevertheless, osimertinib might be introduced in pediatric patients as it has been shown that EGFR mutations play a role in pediatric malignant brain tumors. An exposure-response analysis is lacking in the adult setting. In the absence of an exposure-response target, no appropriate target can be proposed. The geometric mean $\mathrm{C}_{\text {min }}$ of the approved $80 \mathrm{mg}$ q.d. daily dose of $166 \mathrm{ng} / \mathrm{mL}$ could for now be used as a reference to guide future individual pediatric dosing. ${ }^{13}$

\section{VASCULAR ENDOTHELIAL GROWTH FACTOR RECEPTOR}

Vascular endothelial grow th factor receptor (VEGFR) inhibitors are currently used in the treatment of adults with soft-tissue sarcomas (STSs) and renal cell, hepatocellular, and papillary thyroid carcinoma. Renal cell carcinoma (RCC) in children is rare and is different from adult RCC. Different genetic profiles and clinical behavior has been observed in pediatric patients. ${ }^{54}$ Hepatocellular and papillary thyroid carcinoma are rare in the pediatric population; similarity in pathophysiology is therefore not clarified yet for these cancer types. However, it has been shown that VEGFR is overexpressed or plays a biological role in Wilms tumors, hepatocellular carcinoma, hepatoblastoma, (non)rhabdomyosarcoma, STS, Ewing sarcoma, osteosarcoma, and neuroblastoma. ${ }^{55}$ Additionally, promising results have been reported from several small clinical trials treating pediatric patients with VEGFR inhibitors.

\section{Axitinib}

A phase I trial investigating axitinib in pediatric patients with solid tumors has recently been published $(n=18$, age range 5-17 years old). Pediatric patients were treated with a BSAbased dose that was equivalent to the adult flat dose. Toxicity and exposure were found to be similar to adults with RCC. However, an association between steady-state $\mathrm{C}_{\max }$ or $\mathrm{AUC}_{0 \text {-last }}$ and efficacy could not be established. ${ }^{55}$ In adults, a practical target $\mathrm{C}_{\min }$ of $5 \mathrm{ng} / \mathrm{mL}$ has been proposed based on a small study that found a relationship between axitinib $\mathrm{C}_{\min }>5 \mathrm{ng} / \mathrm{mL}$ and tumor response. ${ }^{56}$ Considering the limited data in pediatric patients, the adult cutoff might serve as a preliminary starting point for pediatric dose individualization. The relationship between this target and efficacy in pediatric patients should, however, be assessed, given the differences in biology and pathophysiology of RCC in pediatric and adult patients.

\section{Cabozantinib}

Cabozantinib has been investigated at various dose levels in children with recurrent or refractory solid tumors in a phase I trial ( $n=41$, age range $4-18$ years old). No biomarker changes were observed across dose levels or among responding patients. The recommended phase II dose (RP2D) was $40 \mathrm{mg} / \mathrm{m}^{2}$ q.d., which is equivalent to the $60 \mathrm{mg}$ q.d. adult dose that is registered for RCC. The PK and toxicity profiles at the RP2D ( $40 \mathrm{mg} / \mathrm{m}^{2} \mathrm{q} . \mathrm{d}$.) were similar to that observed in adults with RCC. ${ }^{57}$ The apparent clearance in pediatric patients was $1.1-1.8 \mathrm{~L} /$ hour $/ \mathrm{m}^{2}$ compared with $1.3-2 \mathrm{~L} /$ hour $/ \mathrm{m}^{2}$ in healthy adults. ${ }^{58}$ In a case report, two children with clear cell RCC were treated with cabozantinib on the RP2D. Disease control was shown for over 15 months, which was twice the median PFS observed in an adult phase II trial of cabozantinib in RCC. ${ }^{59}$ While no exposure-response relationship has been established for either adult or pediatric patients, a specific minimum target cannot be proposed for cabozantinib. We recommend to use the mean $\mathrm{C}_{\min }$ of $1125 \mathrm{ng} / \mathrm{mL}$ that was observed in adults with clear cell RCC as an exploratory guide to individualize dosing in pediatric patients. ${ }^{13}$

\section{Lenvatinib}

Several phase I/II studies with lenvatinib in the pediatric setting are currently ongoing. A case report described three patients with papillary thyroid carcinoma who were successfully treated with lenvatinib. ${ }^{60}$ Two out of three patients remained stable for 11 months after start of lenvatinib. A model-based analysis of adult PK-PD data showed a correlation between lenvatinib $\mathrm{AUC}_{0-24 \mathrm{~h}}$ and reduction in tumor size, but a threshold to guide TDM was not reported. ${ }^{61}$ Therefore, TDM in pediatric patients could be guided by the mean $\mathrm{C}_{\text {min }}$ of $51.5 \mathrm{ng} / \mathrm{mL}$ that was proposed as an exploratory minimum target in adults. ${ }^{13}$

\section{Nintedanib}

According to literature, nintedanib has not yet been applied in the pediatric setting. A decrease in soluble VEGFR levels with increasing $\mathrm{C}_{\min }$ was observed in adults in a small phase I study. Additionally, higher nintedanib concentrations have been associated with hepatotoxicity in an exploratory analysis. ${ }^{62}$ Considering the very limited data on nintedanib exposure-response and exposure-toxicity relationships in both pediatric and adult patients, the mean adult $\mathrm{C}_{\min }$ of $13.1 \mathrm{ng} / \mathrm{mL}$ may be used as an exploratory minimum target in pediatric patients. ${ }^{13}$

\section{Pazopanib}

In a phase I study of pazopanib in children $(n=51$, age range $3.8-$ 23.9 years old) with STSs and other refractory solid tumors, a maximum tolerated dose of $450 \mathrm{mg} / \mathrm{m}^{2}$ q.d. has been determined, which is comparable to the adult recommended flat dose of $800 \mathrm{mg}$ q.d. At this dose level, the pediatric day $1 \mathrm{AUC}_{0-24 \mathrm{~h}}$ was similar to that in adults $\left(377.6 \mathrm{mg} / \mathrm{L}^{*}\right.$ hour for children vs. $275.1 \mathrm{mg} / \mathrm{L}^{*}$ hour for adults). An exposure-response relationship could not be established. ${ }^{63}$ 
Pazopanib steady-state plasma drug concentration $\geq 17.5 \mathrm{mg} / \mathrm{L}$ has been suggested as target for optimal in vivo antitumor and antiangiogenic activity in preclinical models. ${ }^{64}$ In a clinical study in adults, a prolonged PFS in patients with $\mathrm{C}_{\min } \geq 20.5 \mathrm{mg} / \mathrm{L} \mathrm{com-}$ pared with patients with a $\mathrm{C}_{\text {min }}$ below this target has been shown. ${ }^{65}$ In a prospective clinical study in adults, the safety and feasibility of $\mathrm{C}_{\text {min }}(\geq 20 \mathrm{mg} / \mathrm{L})$ guided dosing in adults has successfully been demonstrated. ${ }^{66}$ It has been shown that an equal number of patients discontinued treatment due to toxicity in the low $\mathrm{C}_{\min }$ vs. the high $\mathrm{C}_{\text {min }}$ group, and only one patient discontinued treatment after a dose escalation. Considering the exposure-efficacy and exposuretoxicity relationships in adults, a $\mathrm{C}_{\min }$ of $20 \mathrm{mg} / \mathrm{L}$ seems justified as a minimum target for TDM in pediatric patients.

\section{Regorafenib}

In an ongoing phase I trial of regorafenib in pediatric patients with solid tumors ( $n=41$, age range $3-17$ years old), the toxicity profile was similar to adults, with the exception of hematologic events. Hematologic toxicity was seen at a higher rate in heavily pretreated pediatric patients than in adults. ${ }^{67}$ Observed exposure of regorafenib and active metabolites was similar to the adult exposure in the therapeutic dose range, although details were not yet reported. Furthermore, using a physiology-based PK model, the RP2D of $72 \mathrm{mg} / \mathrm{m}^{2}$ was predicted to result in $100 \%$ of adult exposure. An exposure-response relationship has not yet been determined in either adult or pediatric patients. ${ }^{13}$ Based on the limited available data, the best estimate of a minimum target for regorafenib TDM in pediatric patients would be the steady-state mean $\mathrm{C}_{\text {min }}$ of $1.4 \mathrm{mg} / \mathrm{L}$ that was observed in adults.

\section{Sorafenib}

Sorafenib PK has been evaluated in phase I and II studies in pediatric patients. In a population pharmacokinetic analysis based on pooled data from several pediatric clinical trials, the median steady-state $\mathrm{C}_{\min }$ for the RP2D $\left(200 \mathrm{mg} / \mathrm{m}^{2}\right.$ b.i.d.) was $3.89 \mathrm{mg} / \mathrm{L}$ (range $1.39-10.3 \mathrm{mg} / \mathrm{L}, n=37)^{68}$. The pharmacokinetic findings from this analysis were consistent with the PK results from previous pediatric and adult phase I and phase II studies. ${ }^{13,69-71}$ No significant relationship could be identified between the change in VEGF or VEGFR2 and $\mathrm{C}_{\text {min }}$. A solid exposure-response relationship has not yet been described. Considering the observed concentrations in pediatric patients and lacking exposure-response analysis, a $\mathrm{C}_{\min }$ of $3.89 \mathrm{mg} / \mathrm{L}$ seems justified to be the exploratory minimum target concentration in pediatric patients.

\section{Sunitinib}

SunitinibismetabolizedintoitsactivemetaboliteN-desethylsunitinib by cytochrome P450 3A4. For exposure-response analyses and TDM the sum of sunitinib and $\mathrm{N}$-desethylsunitinib concentrations is generally used. Due to the development of myelosuppression and elevated transaminase levels, the RP2D for sunitinib in pediatric patients was established at $15 \mathrm{mg} / \mathrm{m}^{2}$ q.d. on a 4-weeks-on/2-weeksoff schedule, which is lower than the BSA-based adult equivalent $\left(28 \mathrm{mg} / \mathrm{m}^{2}\right.$ q.d.). Hence, the exposure obtained in pediatric patients was lower than in adults. The total (sunitinib $+\mathrm{N}$-desethylsunitinib) steady-state plasma $\mathrm{C}_{\min }$ was $34.9 \mathrm{ng} / \mathrm{mL}(n=11$, range $15.6-$ $90.5 \mathrm{ng} / \mathrm{mL}$ ) in a phase I trial with pediatric patients with solid tumors and $55.4 \mathrm{ng} / \mathrm{mL}(n=20,22.9-109.7 \mathrm{ng} / \mathrm{mL})$ in a phase II trial evaluating sunitinib for the treatment of pediatric high-grade glioma or ependymoma. ${ }^{72,73}$ In a phase I/II study that investigated sunitinib in pediatric patients with advanced GIST, a longer median PFS in patients with higher $\mathrm{C}_{\text {min }}$ (median PFS 2.6 months in lower exposure group and PFS 9.0 months in higher exposure group, $n=6$ ) was found. ${ }^{28}$ In a case series of pediatric patients with GIST, higher sunitinib doses were tolerated compared with the doses used in the clinical trials and toxicity profiles were similar to the ones observed in adult patients (treated with a $50 \mathrm{mg}$ q.d. ( 4 weeks on/2 weeks off) flat dose). ${ }^{74}$ This was attributed to the fact that the children included in clinical studies received more intensive therapy prior to entry in the clinical study compared with the children that were described in the case series. Exposure-response and exposure-toxicity relationships have also extensively been studied in adult patients. ${ }^{13,14}$ Additionally, a TDM feasibility trial in cancer patients confirmed that using a target of $\mathrm{C}_{\min } \geq 50 \mathrm{ng} / \mathrm{mL}$ (sunitinib $+\mathrm{N}$-desethylsunitinib) to guide dosing was successful and safe. ${ }^{75}$ We therefore advise to guide individual dosing in pediatric patients based on the adult target of $\mathrm{C}_{\min } \geq 50 \mathrm{ng} / \mathrm{mL}$ (sunitinib $+\mathrm{N}$-desethylsunitinib) when sunitinib is administered in the 4-weeks-on/2-weeks-off schedule.

\section{Vandetanib}

In children with multiple endocrine neoplasia type $2 \mathrm{~B}$ associated medullary thyroid carcinoma, vandetanib was shown to be well tolerated and highly effective at a dose of $100 \mathrm{mg} / \mathrm{m}^{2}$ q.d. $(n=16){ }^{76,77}$ Exposure reached at this dose level was similar to adults treated with the registered flat dose of $300 \mathrm{mg} / \mathrm{day}$. Mean steady-state plasma drug concentration was $730 \mathrm{ng} / \mathrm{mL}$ in pediatrics and $795 \mathrm{ng} / \mathrm{mL}$ in adults. As a consequence of the small sample size and low frequency of progression of disease in the pediatric study, no exposure-response analyses could be performed. Also, in adults an exposure-response relationship has not yet been published. Therefore, dose escalations could be considered for pediatric patients with an exposure below $730 \mathrm{ng} / \mathrm{mL}$.

\section{SERINE/THREONINE-PROTEIN KINASE B-RAF AND MITOGEN-ACTIVATED PROTEIN KINASE INHIBITORS}

It has extensively been shown that serine/threonine-protein kinase B-raf (BRAF) V600 mutations are important regulators of cell proliferation in adult patients with melanoma. ${ }^{78}$ Similar mutations have been observed in adolescents and adults with melanoma. But similarity in disease pathophysiology could not be concluded as a result of very low enrolment. ${ }^{79}$ Additionally, BRAF V600E mutations have been found in both high-grade and low-grade gliomas. ${ }^{80}$ Given the differences in tumor location, extrapolations from adult melanoma patients to children with brain tumors should be performed carefully.

\section{Vemurafenib}

The pediatric PK of vemurafenib has only been studied in adolescents aged 12-17 years with BRAF mutation-positive melanoma 
$(n=6)$. All patients treated with the adult dose $(960 \mathrm{mg}$ b.i.d. $)$ had a steady-state $\mathrm{C}_{\min }$ above the adult target $\mathrm{C}_{\min }$ of $42 \mathrm{mg} / \mathrm{L}$. In the lower dose level $(720 \mathrm{mg}$ b.i.d.), two out of three patients had a steady-state $\mathrm{C}_{\min }$ below this target. Since this study was terminated due to extremely low enrollment, an exposure-response relationship could not be identified. ${ }^{78}$ Considering the comparable exposure in adolescents compared with adults and presumably similar pathophysiology of melanoma, it seems reasonable to use the threshold of $\mathrm{C}_{\min }>42 \mathrm{mg} / \mathrm{L}$ for TDM of vemurafenib in pediatric patients. ${ }^{13}$

\section{Dabrafenib}

A phase II trial with dabrafenib in combination with trametinib for pediatric V600-positive HGG and low-grade glioma is currently ongoing. An interim analysis showed that the objective response rate in children was $38 \%(n=31)$, including one complete response and 11 partial responses. Additionally, 14 patients had stable disease. ${ }^{81}$ As no pediatric PK data was reported, no specific threshold can be proposed for dabrafenib. The adult target $\mathrm{C}_{\text {min }}$ can, however, serve to guide individual dosing in children. The proposed adult target $\mathrm{C}_{\min }$ in melanoma was based on the median sum of parent dabrafenib and its active hydroxyl metabolite, which was $\mathrm{C}_{\min }$ of $99.6 \mathrm{ng} / \mathrm{mL}^{82}$

\section{Trametinib}

The mitogen-activated protein kinase/extracellular signal-regulated kinase pathway has been characterized as an important pathway in oncogenesis of pilocytic astrocytoma. Only case series of patients $(n=6)$ with pilocytic astrocytomas that were treated with trametinib are available. Partial responses were seen with a good quality of life; only minor toxicities were observed. ${ }^{80} \mathrm{~A}$ population analysis on data from adults with melanoma showed an increasing proportion of responders with increasing exposure to trametinib. This increase showed a plateau at a $\mathrm{C}_{\min }$ of $10 \mathrm{ng} /$ $\mathrm{mL} .{ }^{83}$ Additionally, in an adult phase II study, it was observed that patients with a $\mathrm{C}_{\min }$ above $10.6 \mathrm{ng} / \mathrm{mL}$ had longer PFS than patients below this $\mathrm{C}_{\min }$. Nevertheless, this relationship was not confirmed in phase III trials. Given the absence of reported pediatric PK data, the adult target of $\mathrm{C}_{\min } \geq 10.6 \mathrm{ng} / \mathrm{mL}$ could be used as a preliminary target to individualize pediatric dosing. ${ }^{13}$

\section{Cobimetinib}

A phase I/II clinical trial investigating the safety and PK of cobimetinib in pediatric patients with solid tumors is currently ongoing. ${ }^{84}$ As this is the first clinical trial that investigates cobimetinib in pediatric patients and exposure-response data is absent in adult patients, no specific target for the pediatric population can be proposed. The adult mean $\mathrm{C}_{\min } \geq 127 \mathrm{ng} / \mathrm{mL}$ might be used to guide TDM in pediatrics when treated with cobimetinib for melanoma, for the time being. ${ }^{13}$

\section{OTHER KINASE INHIBITORS USED IN ONCOLOGY \\ Everolimus}

Several in vitro and xenograft studies have shown that rhabdomyosarcoma, neuroblastoma, medulloblastoma/primitive neuroectodermal tumors and pediatric glioblastoma cell lines are sensitive to mTOR inhibition. TDM of everolimus has proven its value in children with non-oncology-related diseases, but a target for TDM in oncology has not yet been reported. ${ }^{11,85}$ In a phase I trial with everolimus in pediatric patients with solid tumors $(n=25$, age range 3-21 years old) it has been shown that the BSA-adjusted dose resulted in an exposure $\left(\mathrm{AUC}_{\mathrm{o} \text {-inf }}\right)$ similar to the exposure observed in adults treated with the registered flat dose of $10 \mathrm{mg}$ q.d. ${ }^{86}$ In addition, it has been shown that the higher dose levels of $3-5 \mathrm{mg} / \mathrm{m}^{2}$ q.d., corresponding to an $\mathrm{AUC}_{0 \text {-inf }}$ of $\geq 200 \mathrm{ng} /$ $\mathrm{mL}^{*}$ hour, were most effective at decreasing AKT phosphorylation. A meta-analysis of adult everolimus phase II oncology trials $(n=945)$ showed that a twofold increase in everolimus $C_{\text {min }}$ was associated with improved tumor size reduction. Also, several analyses of adult RCC patients that were treated with everolimus found trends towards increased PFS for patients with higher $\mathrm{C}_{\min }$ values. ${ }^{87}$ Given the above, the adult threshold of $\mathrm{C}_{\min } \geq 10 \mathrm{ng} /$ $\mathrm{mL}$, which was based on an exposure-response analysis in adults with RCC and endocrine tumors of the pancreas, seems most appropriate to serve as exploratory target for pediatric TDM of everolimus. ${ }^{13}$

\section{Ibrutinib}

Ibrutinib, a Bruton's tyrosine kinase inhibitor, is currently being investigated for the treatment of pediatric relapsed or refractory mature B-cell non-Hodgkin's lymphoma. Therefore, pediatric PK data are not yet available, and a target for TDM should be based on knowledge from adult studies. The target that is used for adults is an $\mathrm{AUC}_{0-24 \mathrm{~h}}$ of $953 \mathrm{ng} / \mathrm{mL}^{*}$ hour for mantle cell lymphoma and an $\mathrm{AUC}_{0-24 \mathrm{~h}}$ of $680 \mathrm{ng} / \mathrm{mL}$ *hour for chronic lymphocytic leuke$\mathrm{mia}$ (no $\mathrm{C}_{\min }$ data reported). However, the implementation of an AUC target in clinical practice is practically challenging. Future clinical studies should therefore be performed in order to establish a well-defined and practical target to guide individual dosing of ibrutinib in pediatric patients.

\section{Idelalisib}

The use of idelalisib, a phosphatidylinositide 3-kinase inhibitor, for the treatment of pediatric patients is very limited. A phase II study aimed to include both adults and pediatric patients older than 12 years of age with Hodgkin's lymphoma, as it was expected that disease pathophysiology was similar in these two populations. However, no pediatric patients were included. ${ }^{88}$ Only adult PK data are therefore available. Adult dose selection was supported by the finding that the $90 \%$ maximal effective concentration of $125 \mathrm{ng} / \mathrm{mL}$ that was needed for in vitro phosphatidylinositide 3-kinase inhibition, was reached by the exposure on the approved dose. ${ }^{89}$ The median $\mathrm{C}_{\min }$ at the approved adult dose was $318 \mathrm{ng} /$ $\mathrm{mL}$, which could be used as exploratory minimum target for TDM in pediatric patients. ${ }^{13}$

\section{Palbociclib}

Palbociclib is a cycline-dependent kinase 4/6 inhibitor. To date, palbociclib has not yet been used for the treatment of pediatric cancers. Nevertheless, a National Cancer Institute-Children's Oncology Group (NCI-COG) Pediatric MATCH (Molecular Analysis for Therapy Choice) trial investigating palbociclib in 
pediatric patients with tumors harboring activating mutations in cell cycle genes is ongoing. ${ }^{90}$ Also, a dose-escalation study with palbociclib in pediatric patients with recurrent/refractory solid tumors is ongoing. While data on the pediatric PK of palbociclib is lacking, individual concentrations could be compared with the adult target of $\mathrm{C}_{\min } \geq 61 \mathrm{ng} / \mathrm{mL}$ in order to further guide individual dosing. ${ }^{13}$

\section{FUTURE PERSPECTIVES}

We explored and summarized the evidence for targets to guide dosing in the pediatric patient population and proposed TDM recommendations for each of the KIs for which a target has been proposed in adult oncology. For none of the KIs, statistically significant exposure-response or exposure-toxicity relationships that provide valid TDM targets for pediatrics have yet been published. This is due to the typically small clinical trial sample sizes, lack of phase II studies, and inherent hurdles to collect PK data in children. Nevertheless, if no differences in disease pathophysiology or pharmacological target are expected between pediatrics and adults, established adult exposure-response relationships could be extrapolated to the pediatric context.

In this review we propose empirical and practical targets for KIs that can be used to individualize dosing in pediatric oncology. Targets are based on the minimally required exposure for efficacy, following the methods of previously published reviews. ${ }^{13-15}$ These values need to be validated; although the molecular target is the same in pediatrics and adults, additional factors may play a role in the successful treatment of the disease in pediatric patients. The role of the driving molecular target in tumor-cell survival may differ among different cancer types. Additionally, as the tumor site may be different, altered drug concentrations at the target site may occur, resulting in a changed exposure-response relationship. In adults, it has been shown that the TDM targets on average correspond to approximately $80 \%$ of the observed mean $\mathrm{C}_{\min }$. It has, therefore, been proposed, while awaiting exposure-response analyses, to use the mean population exposure as a reference target for individual exposure in individual patients when an exposure-response relationship has not yet been established. ${ }^{13,14}$ Additionally, the algorithm presented here (Figure 1) provides also guidance for TDM of KIs in pediatric oncology when applied without prior knowledge on pediatric PK or PD. Several case reports have reported the administration of body weight-based or BSA-based adult equivalent doses to pediatric patients with good clinical results. We strongly urge collecting blood samples in all pediatric patients that are treated with molecular targeted KIs and determine drug concentrations, whenever feasible, in order to gain more insight in the exposure-response and exposure-toxicity relationships.

Exposure-response relationships are to be expected when taking the mechanisms of action and clinical pharmacological characteristics of KIs into account. The few KIs that are currently registered for treatment of children with cancer are administered in a fixed BSA-based dose. We do recognize the superiority of using a BSA-scaled dose over body weight-scaled dosing in pediatric patients. However, this dosing approach originates from the traditional toxicity-based clinical trial designs that were used to guide dose-finding of conventional, mostly intravenously administered, cytotoxic agents. In the currently ongoing clinical trials with KIs for the treatment of pediatric cancer, this approach is still used. As this approach is based on finding the maximum tolerated dose rather than targeting a clinically effective concentration, a risk of overdosing might be introduced, which might hamper the determination of strong exposure-response relationships. However, pediatric clinical trials with innovative designs are emerging to accelerate the drug development in children and increase the availability of drugs for children. For instance, in a phase I study investigating bosutinib in children with CML, dose-finding is based on identifying a dose resulting in a mean exposure similar to the mean exposure that was found in adults. ${ }^{91}$

It is well known that PK can differ between children and adults and may also vary among children of different ages. Drug distribution to various compartments of the body may differ in children since the proportion of body water and fat is age dependent. In addition, the quantity of total plasma proteins is reduced in neonates and young children, which in turn may result in alterations in drug plasma concentrations. Moreover, the metabolism and elimination of drug is influenced by maturational processes. Renal elimination is fully mature at around one year of age, and the maturation of the activity of metabolic enzymes and drug transporters in the GI tract, liver, and brain is complex and still not fully characterized. ${ }^{10}$ Given these maturational changes and the high between-patient variability in exposure of KIs, individualization of dosing of KIs in pediatric oncology may be of great value in order to increase efficacy while regulating toxicity. In addition, administration issues in children, lack of adequate drug formulations, or extemporaneously compounded formulations will influence exposure, supporting the need for TDM.

The tolerability of molecular targeted anticancer agents in pediatric patients is mostly similar to adults. In $75 \%$ of the investigated molecular targeted agents, the pediatric RP2D was 90 $130 \%$ of the BSA-adjusted adult dose. Additionally, available PK parameters for these drugs were similar to those in adults. ${ }^{92}$ This advocates for a treatment strategy in which the dose is increased on an individual basis until the adult target concentration is reached. It should, however, be noted that decreased plasma protein concentrations in pediatric patients might theoretically result in an increase in free drug concentration and thus in a higher risk of developing toxicity. However, when dose reductions are required due to toxicity, TDM can be applied to explore whether this toxicity was related to high exposure. The dose could then be tapered while maintaining a plasma concentration above the target. Hence, this individual patient might still be successfully treated at a lower dose. A similar dose reduction strategy involving TDM could be considered when high exposure is related to long lasting side-effects in pediatrics. To date, such relationships have not yet been published. However, it should be noted that longterm toxicities are seen with molecular targeted agents, such as delayed growth and development. ${ }^{93}$ In pediatric patients treated with VEGFR inhibitors, growth plate toxicity has been observed. Future research in pediatric patients is needed to evaluate the long-term impact of this toxicity on growth and developmental processes, as this information cannot be extrapolated from adult study results. ${ }^{93}$ 
In summary, we have described the available pediatric pharmacokinetics of targeted kinase inhibitors and propose pharmacokinetic targets in order to guide individualized dosing in pediatric cancer patients. For all KIs that were studied, pediatric exposure-response and exposure-toxicity targets are lacking. Therefore, most of the described targets are based on the exposures that are seen in adult patients. Dose adjustments in individual pediatric patients can be based on these targets. Nevertheless, these targets should be validated in prospective randomized clinical trials in order to show their value in increasing treatment efficacy and decreasing toxicity.

\section{FUNDING}

T.P.C.D. was supported by a personal ZonMw/Dutch Research Council (NOW) Veni grant (project no. 91617140). The other authors received no funding for this work.

\section{CONFLICT OF INTEREST}

The authors declared no competing interests for this work.

(c) 2020 The Authors Clinical Pharmacology \& Therapeutics @ 2020 American Society for Clinical Pharmacology and Therapeutics

1. Moreno, L. et al. Early phase clinical trials of anticancer agents in children and adolescents - an ITCC perspective. Nat. Rev. Clin. Oncol. 14, 497-507 (2017).

2. European Medicines Agency. Reflection Paper on the Use of Extrapolation in the Development of Medicines for Paediatrics (European Medicines Agency, Amsterdam, 2018).

3. US Food and Drug Administration. Draft Guidance: General Clinical Pharmacology Considerations for Pediatric Studies for Drugs and Biological Products (US Food and Drug Administration, Silver Spring, MD, 2014).

4. Pearson, A.D.J. et al. From class waivers to precision medicine in paediatric oncology. Lancet Oncol. 18, e394-e404 (2017).

5. Vassal, G. et al. New drugs for children and adolescents with cancer: the need for novel development pathways. Lancet. Oncol. 14, 117-124 (2013).

6. US Food and Drug Administration. Hematology/Oncology (Cancer) Approvals \& Safety Notifications <https://www.fda.gov/drugs/ informationondrugs/approveddrugs/ucm279174.htm> (2020).

7. Terada, T., Noda, S. \& Inui, K.I. Management of dose variability and side effects for individualized cancer pharmacotherapy with tyrosine kinase inhibitors. Pharmacol. Ther. 152, 125-134 (2015).

8. Gao, B., Yeap, S., Clements, A., Balakrishnar, B., Wong, M. \& Gurney, H. Evidence for therapeutic drug monitoring of targeted anticancer therapies. J. Clin. Oncol. 30, 4017-4025 (2012).

9. Widmer, N. et al. Review of therapeutic drug monitoring of anticancer drugs part two-targeted therapies. Eur. J. Cancer 50, 2020-2036 (2014).

10. Kearns, G.L., Abdel-Rahman, S.M., Alander, S.W., Blowey, D.L., Leeder, J.S. \& Kauffman, R.E. Developmental pharmacologydrug disposition, action, and therapy in infants and children. $N$. Engl. J. Med. 349, 1157-1167 (2003).

11. Shipkova, M. et al. Therapeutic drug monitoring of everolimus: a consensus report. Ther. Drug Monit. 38, 143-169 (2016).

12. van Luin, M., Kuks, P.F. \& Burger, D.M. Use of therapeutic drug monitoring in HIV disease. Curr. Opin. HIV AIDS 3, 266-271 (2008).

13. Verheijen, R.B., Huixin, Y., Schellens, J.H.M., Beijnen, J.H., Steeghs, N. \& Huitema, A.D.R. Practical recommendations for therapeutic drug monitoring of kinase inhibitors in oncology. Clin. Pharmacol. Ther. 102, 765-776 (2017).

14. Yu, H., Steeghs, N., Nijenhuis, C.M., Schellens, J.H.M., Beijnen, J.H. \& Huitema, A.D.R. Practical guidelines for therapeutic drug monitoring of anticancer tyrosine kinase inhibitors: Focus on the pharmacokinetic targets. Clin. Pharmacokinet. 53, 305-325 (2014).

15. Groenland, S.L. et al. Therapeutic drug monitoring of oral antihormonal drugs in oncology. Clin. Pharmacokinet. 58, 299-308 (2019).

16. Carpenter, E.L. \& Mossé, Y.P. Targeting ALK in neuroblastomapreclinical and clinical advancements. Nat. Rev. Clin. Oncol. 9, 391-399 (2012).

17. Mossé, Y.P. et al. Targeting ALK with crizotinib in pediatric anaplastic large cell lymphoma and inflammatory myofibroblastic tumor: A Children's Oncology Group study. J. Clin. Oncol. 35 , 3215-3221 (2017).

18. Balis, F.M. et al. First-dose and steady-state pharmacokinetics of orally administered crizotinib in children with solid tumors: a report on ADVL0912 from the Children's Oncology Group Phase 1/Pilot Consortium. Cancer Chemother. Pharmacol. 79, 181-187 (2017).

19. Geoerger, B. et al. Phase I study of ceritinib in pediatric patients (Pts) with malignancies harboring a genetic alteration in ALK $(A L K+)$ : Safety, pharmacokinetic (PK), and efficacy results. J. Clin. Oncol. 33, 10005-10005 (2015).

20. Committee for Medicinal Products for Human Use (CHMP), European Medicines Agency. Ceritinib European Public Assessment Report Vol. 44 (European Medicines Agency, Amsterdam, 2015).

21. Center for Drug Evaluation and Research, US Food and Drug Administration.Alectinib Clinical Pharmacology and Biopharmaceutics Review <http://www.accessdata.fda.gov/ drugsatfda_docs/nda/2015/2084340rig1s000ClinPharmR.pdf> (2016).

22. Hijiya, N., Schultz, K.R., Metzler, M., Millot, F. \& Suttorp, M. Pediatric chronic myeloid leukemia is a unique disease that requires a different approach. Blood 127, 392-399 (2016).

23. d.I. Fuente, J. et al. Managing children with chronic myeloid leukaemia (CML) Recommendations for the management of CML in children and young people up to the age of 18 years. Br. J. Haematol. 167, 33-47 (2014).

24. Petain, A. et al. Population pharmacokinetics and pharmacogenetics of imatinib in children and adults. Clin. Cancer Res. 14, 7102-7109 (2008).

25. Menon-Andersen, D. et al. Population pharmacokinetics of imatinib mesylate and its metabolite in children and young adults. Cancer Chemother. Pharmacol. 63, 229-238 (2009).

26. Suttorp, M., Bornhäuser, M., Metzler, M., Millot, F. \& Schleyer, E. Pharmacology and pharmacokinetics of imatinib in pediatric patients. Expert Rev. Clin. Pharmacol. 11, 219-231 (2018).

27. Geoerger, B. et al. Target-driven exploratory study of imatinib mesylate in children with solid malignancies by the Innovative Therapies for Children with Cancer (ITCC) European Consortium. Eur. J. Cancer 45, 2342-2351 (2009).

28. Verschuur, A.C. et al. Sunitinib in pediatric patients with advanced gastrointestinal stromal tumor: results from a phase I/II trial. Cancer Chemother. Pharmacol. 84, 41-50 (2019).

29. Demetri, G.D. et al. Imatinib plasma levels are correlated with clinical benefit in patients with unresectable/metastatic gastrointestinal stromal tumors. J. Clin. Oncol. 27, 3141-3147 (2009).

30. Slayton, W.B. et al. Dasatinib plus intensive chemotherapy in children, adolescents, and young adults with Philadelphia chromosome-positive acute lymphoblastic leukemia: results of Children's Oncology Group trial AALL0622. J. Clin. Oncol. 36 2306-2313 (2018).

31. Zwaan, C.M. et al. Dasatinib in children and adolescents with relapsed or refractory leukemia: results of the CA180-018 phase I dose-escalation study of the Innovative Therapies for Children with Cancer Consortium. J. Clin. Oncol. 31, 2460-2468 (2013).

32. Ishida, Y. et al. Pharmacokinetics and pharmacodynamics of dasatinib in the chronic phase of newly diagnosed chronic myeloid leukemia. Eur. J. Clin. Pharmacol. 72, 185-193 (2016).

33. ClinicalTrials.gov. A Pharmacokinetic (PK) Study of Nilotinib in Pediatric Patients with Philadelphia Chromosome-positive $(\mathrm{Ph}+)$ Chronic Myelogenous Leukemia (CML) or Acute Lymphoblastic 
Leukemia (ALL) <https://clinicaltrials.gov/ct2/show/study/NCT01 077544>.

34. Giles, F.J. et al. Nilotinib population pharmacokinetics and exposure-response analysis in patients with imatinib-resistant or -intolerant chronic myeloid leukemia. Eur. J. Clin. Pharmacol. 69, 813-823 (2013).

35. Committee for Medicinal Products for Human Use (CHMP), European Medicines Evaluation Agency. Bosutinib European Public Assessment Report <http://www.ema.europa.eu/docs/ en_GB/document_library/EPAR_-_Public_assessment_report/ human/002373/WC500141745.pdf> (2013).

36. Cortes, J.E. et al. Phase 2 trial of Ponatinib in Philadelphia chromosome-positive Leukemias. N Engl. J. Med. 369, 1783-1796 (2013).

37. Center for Drug Evaluation and Research, US Food and Drug Administration. Ponatinib Clinical Pharmacology and Biopharmaceutics Review <https://www.accessdata.fda.gov/ drugsatfda_docs/nda/2012/2034690rig1s000ClinPharmR. pdf $>$.

38. Yamamoto, M., Hori, T., Igarashi, K., Shimada, H. \& Tsutsumi, $\mathrm{H}$. Response to ponatinib before hematopoietic stem cell transplantation in a child with relapsed Philadelphia chromosomepositive acute lymphoblastic leukemia. Pediatr. Int. 60, 85-87 (2018).

39. Nickel, R.S., Daves, M. \& Keller, F. Treatment of an adolescent with chronic myeloid leukemia and the T315I mutation with ponatinib. Pediatr. Blood Cancer 62, 2050-2051 (2015).

40. Geoerger, B. et al. Innovative therapies for children with cancer pediatric phase I study of erlotinib in brainstem glioma and relapsing/refractory brain tumors. Neuro. Oncol. 13, 109-118 (2011).

41. Geyer, J.R. et al. A phase I and biology study of gefitinib and radiation in children with newly diagnosed brain stem gliomas or supratentorial malignant gliomas. Eur. J. Cancer 46, 3287-3293 (2010).

42. Daw, N.C. et al. Phase I and pharmacokinetic study of gefitinib in children with refractory solid tumors: a Children's Oncology Group study. J. Clin. Oncol. 23, 6172-6180 (2005).

43. Bredel, M., Pollack, I.F., Hamilton, R.L. \& James, C.D. Epidermal growth factor receptor expression and gene amplification in highgrade non-brainstem gliomas of childhoos. Clin. Cancer Res. 5, 1786-1792 (1999).

44. Paugh, B.S. et al. Integrated molecular genetic profiling of pediatric high-grade gliomas reveals key differences with the adult disease. J. Clin. Oncol. 28, 3061-3068 (2010).

45. Ranson, M. et al. ZD1839, a selective oral epidermal growth factor receptor-tyrosine kinase inhibitor, is well tolerated and active in patients with solid, malignant tumors: results of a phase I trial. J. Clin. Oncol. 20, 2240-2250 (2002).

46. Zhao, Y.-Y. et al. The relationship between drug exposure and clinical outcomes of non-small cell lung cancer patients treated with gefitinib. Med. Oncol. 28, 697-702 (2011).

47. White-Koning, M. et al. Population analysis of erlotinib in adults and children reveals pharmacokinetic characteristics as the main factor explaining tolerance particularities in children. Clin. Cancer Res. 17, 4862-4871 (2011).

48. Reddick, S.J. et al. Pharmacokinetics and safety of erlotinib and its metabolite OSI-420 in infants and children with primary brain tumors. Cancer Chemother. Pharmacol. 84, 829-838 (2019).

49. White-Koning, M. et al. Population analysis of Erlotinib and children reveals pharmacokinetic characteristics as the main factor explaining tolerance particularities in children. Clin. Cancer Res. 17, 4862-4871 (2011).

50. DeWire, M. et al. An open-label, two-stage, phase II study of bevacizumab and lapatinib in children with recurrent or refractory ependymoma: a collaborative ependymoma research network study (CERN). J. Neurooncol. 123, 85-91 (2015).

51. Fouladi, M. et al. A molecular biology and phase II trial of lapatinib in children with refractory CNS malignancies: A pediatric brain tumor consortium study. J. Neurooncol. 114, 173-179 (2013).

52. Center for Drug Evaluation and Research, US Food and Drug Administration. Afatinib Clinical Pharmacology and
Biopharmaceutics Review (US Food and Drug Administration, Silver Spring, MD, 2012).

53. Wind, S., Schmid, M., Erhardt, J., Goeldner, R.-G. \& Stopfer, P. Pharmacokinetics of afatinib, a selective irreversible ErbB family blocker, in patients with advanced solid tumours. Clin. Pharmacokinet. 52, 1101-1109 (2013).

54. Geller, J.I. et al. Characterization of adolescent and pediatric renal cell carcinoma: a report from the Children's Oncology Group study AREN03B2. Cancer 121, 2457-2464 (2015).

55. Geller, J.I. et al. A study of axitinib, a VEGF receptor tyrosine kinase inhibitor, in children and adolescents with recurrent or refractory solid tumors: A Children's Oncology Group Phase 1 and Pilot Consortium Trial (ADVL1315). Cancer 124, 4548-4555 (2018).

56. Tsuchiya, N. et al. Association of pharmacokinetics of axitinib with treatment outcome and adverse events in advanced renal cell carcinoma patients. In Genitourinary Cancers Symposium. J. Clin. Oncol. 33, 2015 (2015).

57. Chuk, M.K. et al. A phase 1 study of cabozantinib in children and adolescents with recurrent or refractory solid tumors, including CNS tumors: Trial ADVL1211, a report from the Children's Oncology Group. Pediatr. Blood Cancer 65, 1-7 (2018).

58. Nguyen, L., Benrimoh, N., Xie, Y., Offman, E. \& Lacy, S. Pharmacokinetics of cabozantinib tablet and capsule formulations in healthy adults. Anticancer. Drugs 27, 669-678 (2016).

59. Wedekind, M.F., Ranalli, M. \& Shah, N. Clinical efficacy of cabozantinib in two pediatric patients with recurrent renal cell carcinoma. Pediatr. Blood Cancer 64, 4-7 (2017).

60. Mahajan, P. et al. Response to lenvatinib in children with papillary thyroid carcinoma. Thyroid 28, 1450-1454 (2018).

61. Committee for Medicinal Products for Human Use (CHMP), European Medicines Agency. Lenvatinib European public assessment report <http://www.ema.europa.eu/docs/en_GB/ document_library/EPAR_-_Public_assessment_report/human/ 003727/WC500188676.pdf> (2015).

62. Okamoto, I. et al. Phase I safety, pharmacokinetic, and biomarker study of BIBF 1120, an oral triple tyrosine kinase inhibitor in patients with advanced solid tumors. Mol. Cancer Ther. $\mathbf{9}$, 2825-2833 (2010).

63. Glade Bender, J.L. et al. Phase I pharmacokinetic and pharmacodynamic study of pazopanib in children with soft tissue sarcoma and other refractory solid tumors: a children's oncology group phase I consortium report. J. Clin. Oncol. 31, 3034-3043 (2013).

64. Kumar, R. et al. Pharmacokinetic-pharmacodynamic correlation from mouse to human with pazopanib, a multikinase angiogenesis inhibitor with potent antitumor and antiangiogenic activity. Mol. Cancer Ther. 6, 2012-2021 (2007).

65. Suttle, A.B. et al. Relationships between pazopanib exposure and clinical safety and efficacy in patients with advanced renal cell carcinoma. Br. J. Cancer 111, 1909-1916 (2014).

66. Verheijen, R.B. et al. Individualized pazopanib dosing: a prospective feasibility study in cancer patients. Clin. Cancer Res. 22, 5738-5746 (2016).

67. Geoerger, B. et al. Phase I dose-escalation and pharmacokinetic (PK) study of regorafenib in pediatric patients with recurrent or refractory solid malignancies. J. Clin. Oncol. 34, 10542-10542 (2016).

68. Inaba, H. et al. Sorafenib population pharmacokinetics and skin toxicities in children and adolescents with refractory/relapsed leukemia or solid tumor malignancies. Clin. Cancer Res. 25, 7320-7330 (2019).

69. Reed, D.R. et al. Pediatric phase I trial of oral sorafenib and topotecan in refractory or recurrent pediatric solid malignancies. Cancer Med. 5, 294-303 (2016).

70. Karajannis, M.A. et al. Phase II study of sorafenib in children with recurrent or progressive low-grade astrocytomas. Neuro. Oncol. 16, 1408-1416 (2014).

71. Kim, A. et al. Phase 2 trial of Sorafenib in children and young adults with refractory solid tumors: a report from the Children's oncology group. Pediatr. Blood Cancer 62, 1562-1566 (2015).

72. DuBois, S.G. et al. Phase I and pharmacokinetic study of sunitinib in pediatric patients with refractory solid tumors: a Children's Oncology Group study. Clin. Cancer Res. 17, 5113-5122 (2011). 
73. Wetmore, C. et al. Phase II evaluation of sunitinib in the treatment of recurrent or refractory high-grade glioma or ependymoma in children: a Children's Oncology Group study ACNS1021. Cancer Med. 5, 1416-1424 (2016).

74. Janeway, K.A. et al. Sunitinib treatment in pediatric patients with advanced GIST following failure of Imatinib. Pediatr. Blood Cancer 52, 767-771 (2009).

75. Lankheet, N.A.G. et al. Pharmacokinetically guided sunitinib dosing: a feasibility study in patients with advanced solid tumours. Br. J. Cancer 110, 2441-2449 (2014).

76. Fox, E. et al. Vandetanib in children and adolescents with multiple endocrine neoplasia type $2 \mathrm{~b}$ associated medullary thyroid carcinoma. Clin. Cancer Res. 19, 4239-4248 (2013).

77. Fallahi, P. et al. The safety and efficacy of vandetanib in the treatment of progressive medullary thyroid cancer. Expert Rev. Anticancer Ther. 16, 1109-1118 (2016).

78. Chisholm, J.C. et al. BRIM-P: A phase I, open-label, multicenter, dose-escalation study of vemurafenib in pediatric patients with surgically incurable, BRAF mutation-positive melanoma. Pediatr. Blood Cancer 65, 1-9 (2018).

79. Bautista, F. et al. Vemurafenib in pediatric patients With BRAFV600E mutated high-grade Gliomas. Pediatr. Blood Cancer 61, 1101-1103 (2014).

80. Kondyli, M. et al. Trametinib for progressive pediatric low-grade gliomas. J. Neurooncol. 140, 435-444 (2018).

81. Hargrave, D.R. et al. Dabrafenib in pediatric patients with BRAF V600-positive high-grade glioma (HGG). J. Clin. Oncol. 36(suppl. 15), 10505-10505 (2018).

82. Center for Drug Evaluation and Research, US Food and Drug Administration. Dabrafenib clinical pharmacology and biopharmaceutics review <http://www.accessdata.fda.gov/drugs atfda_docs/nda/2013/2028060rig1s000ClinPharmR.pdf> (2013).

83. Ouellet, D. et al. Population pharmacokinetics and exposureresponse of trametinib, a MEK inhibitor, in patients with BRAF V600 mutation-positive melanoma. Cancer Chemother. Pharmacol. 77, 807-817 (2016).
84. ClinicalTrials.gov. Safety and pharmacokinetics of cobimetinib in pediatric and young adult participants with previously treated solid tumors (iMATRIXcobi) <https://clinicaltrials.gov/ct2/show/ NCT02639546>.

85. Krueger, D.A. et al. Everolimus for subependymal giant-cell astrocytomas in tuberous sclerosis. N. Engl. J. Med. 363, 1801-1811 (2010).

86. Fouladi, M. et al. Phase I study of everolimus in pediatric patients with refractory solid tumors. J. Clin. Oncol. 25, 4806-4812 (2007).

87. Ravaud, A., Urva, S.R., Grosch, K., Cheung, W.K., Anak, O. \& Sellami, D.B. Relationship between everolimus exposure and safety and efficacy: meta-analysis of clinical trials in oncology. Eur. J. Cancer 50, 486-495 (2014).

88. Gopal, A.K. et al. Phase II study of idelalisib, a selective inhibitor of PI3K $\delta$, for relapsed/refractory classical Hodgkin lymphoma. Ann. Oncol. 28, 1057-1063 (2017).

89. Ramanathan, S., Jin, F., Sharma, S. \& Kearney, B.P. Clinical pharmacokinetic and pharmacodynamic profile of Idelalisib. Clin. Pharmacokinet. 55, 33-45 (2016).

90. ClinicalTrials.gov. Palbociclib in treating patients with relapsed or refractory Rb positive advanced solid tumors, non-Hodgkin lymphoma, or histiocytic disorders with activating alterations in cell cycle genes (a pediatric MATCH treatment trial) <https://clini caltrials.gov/ct2/show/NCT03526250>.

91. A phase I/II study of Bosutinib in pediatric patients with Chronic Myeloid Leukemia who are resistant or intolerant to at least one prior Tyrosine Kinase Inhibitor therapy, ITCC-054/ AAML1621 <https://www.clinicaltrialsregister.eu/ctr-search/trial/ 2015-002>.

92. Paoletti, X., Geoerger, B., Doz, F., Baruchel, A., Lokiec, F. \& Le Tourneau, C. A comparative analysis of paediatric dose-finding trials of molecularly targeted agent with adults' trials. Eur. J. Cancer 49, 2392-2402 (2013).

93. Voss, S.D. et al. Growth plate abnormalities in pediatric cancer patients undergoing phase 1 anti-angiogenic therapy: a report from the Children's Oncology Group phase I consortium. Pediatr. Blood Cancer 62, 45-51 (2015). 